\title{
RELATIVE AND INTERACTIVE EFFECTS OF PLANT AND GRAZER RICHNESS IN A BENTHIC MARINE COMMUNITY
}

\author{
John F. Bruno, ${ }^{1,3}$ Katharyn E. Boyer,,${ }^{1,4}$ J. Emmett Duffy, ${ }^{2}$ and Sarah C. LeE ${ }^{1}$ \\ ${ }^{1}$ Department of Marine Sciences, University of North Carolina, Chapel Hill, North Carolina 27599-3300 USA \\ ${ }^{2}$ School of Marine Sciences, College of William and Mary, Gloucester Point, Virginia 23062-1346 USA
}

\begin{abstract}
The interactive effects of changing biodiversity of consumers and their prey are poorly understood but are likely to be important under realistic scenarios of biodiversity loss and gain. We performed two factorial manipulations of macroalgal group (greens, reds, and browns) and herbivore species (amphipods, sea urchin, and fish) composition and richness in outdoor mesocosms simulating a subtidal, hard-substratum estuarine community in North Carolina, USA. In the experiment where grazer richness treatments were substitutive, there were no significant effects of algal or herbivore richness on final algal biomass. However, in the experiment in which grazer treatments were additive (i.e., species-specific densities were held constant across richness treatments), we found strong independent and interactive effects of algal and herbivore richness. Herbivore polycultures reduced algal biomass to a greater degree than the sum of the three herbivore monocultures, indicating that the measured grazer richness effects were not due solely to increased herbivore density in the polycultures. Taking grazer density into account also revealed that increasing algal richness dampened grazer richness effects. Additionally, the effect of algal richness on algal biomass accumulation was far stronger when herbivores were absent, suggesting that grazers can utilize the increased productivity and mask the positive effects of plant biodiversity on primary production. Our results highlight the complex independent and interactive effects of biodiversity between adjacent trophic levels and emphasize the importance of performing biodiversity-ecosystem functioning experiments in a realistic multi-trophic context.
\end{abstract}

Key words: amphipods; biodiversity; complementarity; diversity; ecosystem function; grazers, herbivory; macroalgae; production; richness.

\section{INTRODUCTION}

Most investigations of the role of biodiversity in regulating ecosystem processes have been based on manipulations of species composition and richness within a single trophic level, primarily terrestrial plants (Tilman et al. 2001, Hooper et al. 2005), aquatic microbes (Naeem and $\mathrm{Li}$ 1998), and marine macrophytes (Callaway et al. 2003, Hughes and Stachowicz 2004, Reusch et al. 2005, Bruno et al. 2006). Although several early studies focused on the diversity of aquatic detritus consumers (Jonsson and Malmqvist 2000, Ruesink and Srivastava 2001) and soil fauna (Mikola and Setälä 1998), more recently ecologists have expanded this research to consider the effects of changing the biodiversity of herbivores and carnivores, primarily in coastal marine (Duffy et al. 2003, 2005, Bruno and O'Connor 2005, O'Connor and Crowe 2005, Byrnes et al. 2006, O'Connor and Bruno 2007) and agricultural

Manuscript received 17 August 2007; revised 14 January 2008; accepted 31 January 2008. Corresponding Editor: P. T. Raimondi.

${ }^{3}$ E-mail: jbruno@unc.edu

${ }^{4}$ Present address, Romberg Tiburon Center for Environmental Studies and Department of Biology, San Francisco State University, 3152 Paradise Drive, Tiburon, California 94920 USA. systems (Cardinale et al. 2003). Because spatial and temporal variation in biodiversity typically occurs throughout food webs, understanding biodiversity effects in real-world ecosystems will require coordinated examinations of multiple trophic levels. However, few experiments have simultaneously manipulated the richness of adjacent trophic levels (but see Fox 2004, Gamfeldt et al. 2005) so that the independent and interactive effects of the biodiversity of consumers and their prey could be untangled (Duffy et al. 2007).

Synthesis of empirical results from plant biodiversity experiments provides solid support for the prediction that increasing the species or functional group richness of primary producers, on average, increases total resource use and biomass production (Tilman et al. 2001, Balvanera et al. 2006, Cardinale et al. 2006). Predicted consequences of changing richness at the herbivore level are conceptually similar (but see Long et al. 2007, Schmitz 2007), but are expected to affect a given response variable in the opposite direction as plant biodiversity. Theory predicts that increasing herbivore richness should reduce total plant biomass due to a variety of mechanisms including resource partitioning or facilitation among herbivores and the inclusion of highly effective or generalist grazers (Cardinale et al. 2002, Duffy 2002, Holt and Loreau 2002, Duffy et al. 2007). But focusing on interactions between trophic levels also 
introduces added complexity (e.g., Thebault and Loreau 2003). For example, intense grazing can also depress plant diversity and facilitate invasion of grazingresistant species (Lubchenco 1978, Leibold 1996, Leibold et al. 1997). Predicted declines in plant biomass with increasing grazer richness have been documented in laboratory experiments using protists and bacteria when a single algal species supported the food web (Naeem and $\mathrm{Li}$ 1998) and in mesocosm experiments based on estuarine eelgrass ecosystems (Duffy et al. 2003). In other experiments, however, resistant algal species came to dominate under heavy grazing, compensating for the loss of edible species and eliminating the relationship between grazer richness and total plant biomass (Norberg 2000), or plant biomass was largely controlled by herbivore composition and grazer richness had no measurable effects (O'Connor and Crowe 2005).

One general inference of current theory and recent empirical studies is that varying plant and herbivore richness should influence ecosystem processes in opposite directions and could thus have counteracting effects (Worm and Duffy 2003, Duffy et al. 2007). Furthermore, richness at one trophic level could in theory influence the effects of richness at adjacent or nonadjacent trophic levels. For example, increasing the richness of plants and other prey is predicted to reduce top-down control in general (Duffy 2002) and could also dampen the effect of increasing predator richness. The first of these hypotheses is supported by a meta-analysis of aquatic algal-grazer experiments, which found that grazer impacts on algal biomass are typically lower when algal assemblages are more diverse (Hillebrand and Cardinale 2004). Beyond these direct trophic interactions, increasing plant richness could also indirectly benefit herbivores by increasing habitat complexity, thereby reducing the foraging efficiency of carnivores. The significance of such emergent, trophically mediated and bidirectional processes remains uncertain, however, because simultaneous, factorial manipulation of plant and consumer diversity in the same experiment have rarely been attempted, and to date only with microbial systems (Fox 2004, Gamfeldt et al. 2005). Thus, virtually nothing is known about how biodiversity effects at one trophic level are dampened or magnified by changes in the relative richness of adjacent trophic levels.

The purpose of this study was to measure the independent and interactive effects of primary producer group and herbivore species richness in controlling biomass accumulation in a benthic marine ecosystem. We used a diverse assemblage of marine macroalgae and their herbivores, including amphipods, sea urchins, and fishes in two mesocosm experiments in North Carolina. A persistent question in evaluating effects of consumer diversity is the degree to which aggregate consumer abundance scales positively with consumer diversity, vs. remaining relatively constant with diversity as a result, for example, of interspecific competition (or intraguild predation) among consumers (Bruno and Cardinale 2008). These two extremes can be simulated, respectively, by additive and substitutive experimental designs. To explore both scenarios, one of our experiments used an additive design for the herbivore treatments, in which three-species polycultures had total initial abundance equal to the sum of the three monocultures. The other experiment used a substitutive design, in which total initial herbivore abundance was constant across treatments. Our results indicate that algal group and herbivore species effects depend on the composition and richness of the adjacent trophic level and are also likely influenced substantially by environmental context and intraguild predation.

\section{Materials And Methods}

We conducted two similar outdoor mesocosm experiments at the University of North Carolina's Institute of Marine Science (IMS) in Morehead City, North Carolina (additive experiment, 18 October-14 November 2002; substitutive experiment, 25 August-14 September 2003). We manipulated algal and herbivore composition and richness in a fully factorial design using the most common species in local hard substratum environments at the time of each experiment (Fig. 1). The four algal treatments included three algal groups of one or two species, corresponding to the divisions Rhodophyta, Chlorophyta, and Phaeophyta (i.e., red, green, and brown algae, respectively) and a mixture of all three groups, i.e., polycultures (Fig. 1). These broad taxonomic groups also constitute functional groups in that they are differentially palatable to the herbivores we used (Hay et al. 1987, Duffy and Hay 2000). Functional grouping permitted us to include all dominant species from the system and realistic levels of algal diversity without the experiment becoming logistically unmanageable. Algal group composition and richness were manipulated by attaching algal thalli to $25 \times 25 \mathrm{~cm}$ Vexar (Dupont) plastic mesh screens (5-mm openings) with small cable ties, such that algae floated upward in a natural orientation. Algal species and group richness, and biomass and grazer richness, and densities used in the experiments were comparable to local field values (Hay and Sutherland 1988, Bruno and O'Connor 2005, Bruno et al. 2005). Initial total algal biomass was held constant across the group and polyculture treatments (i.e., a substitutive design). Small invertebrate grazers were initially removed from the algae by placing the algae screens in a bath of dilute insecticide (Sevin [1naphthyl-n-methyl-carbamate]; Bayer CropScience, Calgary, Alberta, Canada) and rinsing several times to remove residue (Carpenter 1986, Bruno et al. 2005).

The three dominant functional groups of benthic herbivores in this system are invertebrate mesograzers, urchins, and omnivorous fish. We used the most abundant and/or important species from each group in the experiments, based on extensive previous experimental work and field surveys (Hay and Sutherland 
Additive mesocosm experiment (2002)

( $n=5$, duration $=4$ weeks, starting wet algal mass $=40 \mathrm{~g}$, substitutive design for macroalgae and additive design for the herbivore treatment)

\begin{tabular}{|l|l|}
$\begin{array}{l}\text { Macroalgal group } \\
\text { identity and richness }\end{array}$ & $\begin{array}{l}\text { Herbivore species } \\
\text { identity and richness }\end{array}$ \\
$\begin{array}{l}\text { Red } \\
\text { Pracilaria tikvahiae }\end{array}$ & $\begin{array}{l}\text { No herbivores } \\
\text { Fish (2) } \\
\text { Lagodon rhomboides }\end{array}$ \\
\hline $\begin{array}{l}\text { Green } \\
\text { Enteromorpha sp. }\end{array}$ & $\begin{array}{l}\text { Urchins (1) } \\
\text { Arbacia punctulata }\end{array}$ \\
\hline $\begin{array}{l}\text { Brown } \\
\text { Sargassum filipendula }\end{array}$ & $\begin{array}{l}\text { Amphipods (40) } \\
\text { Ampithoe longimana }\end{array}$ \\
\hline $\begin{array}{l}\text { Mixture } \\
\text { (13.33 g per group) }\end{array}$ \\
\hline
\end{tabular}

Substitutive mesocosm experiment (2003) ( $n=8$, duration $=3$ weeks, starting wet algal mass $=36 \mathrm{~g}$, substitutive design for both treatments)

\section{Macroalgal group identity and richness}
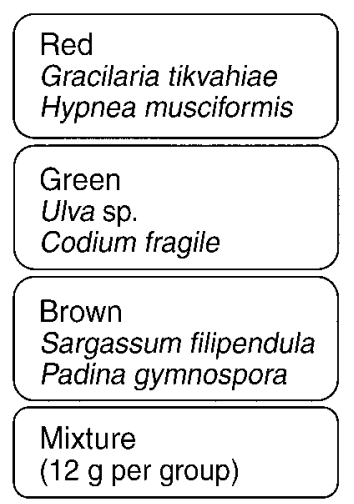

Herbivore species identity and richness

\begin{tabular}{|c|}
\hline No herbivores \\
\hline $\begin{array}{l}\text { Fish (6) } \\
\text { Lagodon rhomboides }\end{array}$ \\
\hline $\begin{array}{l}\text { Urchins (3) } \\
\text { Arbacia punctulata }\end{array}$ \\
\hline $\begin{array}{l}\text { Amphipods ( } 210 \text { ) } \\
\text { Ampithoe longimana }\end{array}$ \\
\hline $\begin{array}{l}\text { Mixture } \\
\text { ( } 2 \text { fish, } 1 \text { urchin, } \\
70 \text { amphipods) }\end{array}$ \\
\hline
\end{tabular}

FIG. 1. Schematic of the design of the additive and substitutive mesocosm experiments at the University of North Carolina's Institute of Marine Science in Morehead City, North Carolina, USA. For the herbivore species, the numbers in parentheses are the number of individuals.

1988, Miller and Hay 1996): the mesograzer Ampithoe longimana, the pinfish Lagodon rhomboides, and the urchin Arbacia punctulata. A. longimana is a relatively sedentary, tube-building amphipod and a dominant mesograzer in North Carolina (Duffy and Hay 2000). It preferentially consumes brown macroalgae, but also feeds on red and green macroalgae, diatoms, detritus, and vascular plant material (Duffy and Hay 1991, 1994). Omnivorous pinfish feed on small crustaceans as well as green and red algae, while avoiding chemically defended brown algae (Holmlund et al. 1990, Duffy and Hay 2000, Bruno and O'Connor 2005). Similarly, A. punctu- lata consumes green and red algae and generally avoids brown species (Hay et al. 1987, Cronin and Hay 1996a, b).

Both experiments included four grazer treatments (amphipod, pinfish, and urchin monocultures and polycultures of all three species; Fig. 1). In the substitutive experiment we reduced the abundance of each grazer species by two-thirds in the mixture treatment, thus holding total grazer density constant across all treatments. There are advantages and disadvantages of additive and substitutive designs (Cardinale et al. 2003). Because density is held constant across richness treatments in a substitutive design, density and richness are not confounded as they are in an additive design (Sih et al. 1998). The trade-off is that because intraspecific densities are reduced in polycultures in a substitutive design, negative intraspecific interactions might be artificially relaxed. Whether this constitutes an artifact or a legitimate mechanism driving richness effects depends on how species interactions within a guild affect intraspecific densities in nature (Aquilino et al. 2005, Bruno and O'Connor 2005, O'Connor and Bruno 2007).

The experiments were performed in two similar mesocosm systems at IMS (described in Bruno and O'Connor 2005). The mesocosms were clear plastic tubs $(60 \mathrm{~L}$ in the additive experiment and $30 \mathrm{~L}$ in the substitutive experiment) that were situated within shallow tanks (6 tubs per tank in the additive experiment and 20 tubs per tank in the substitutive experiment) that collected outflow and helped to maintain a constant temperature. Dump buckets placed above the mesocosms gradually filled with seawater and periodically emptied into the mesocosms below, simulating the turbulence of local rocky substratum environments. Seawater from the adjacent Bogue Sound was continually pumped into the dump buckets after passing through a fine $(100 \mu \mathrm{m})$ mesh filter to minimize the immigration of grazers. Heavy plastic (Vexar) screens with attached algae were placed in the mesocosms (one screen each) $30 \mathrm{~cm}$ below the water's surface, then the appropriate herbivores were added after collection the same day, or in the case of amphipods, after being cultured for several weeks. The mesocosms were originally randomly assigned to tanks and positions and were then rearranged in the tanks every five days. At the end of the experiments we quantified net increases or losses of algal tissue due to both growth and herbivory by measuring final algal wet biomass, including algae attached to screens and fragments that had become detached but remained in the mesocosms. Excess water was removed from the algae using a salad spinner $(60$ revolutions). Final algal dry mass was also measured, but was highly correlated with final wet mass (adjusted $R^{2}=0.93, n=152 ; 2003$ data) and is not reported here.

Data were transformed as necessary to meet the statistical assumptions of ANOVA. For each experiment we conducted a two-factor ANOVA on percentage 
TABLE 1. Treatment effects in each mesocosm experiment on the percentage change in algal wet mass, analyzed by two-factor ANOVA (both factors fixed).

\begin{tabular}{|c|c|c|c|c|c|}
\hline Factor & SS & $\mathrm{df}$ & $F$ & $P$ & $\omega^{2}$ \\
\hline \multicolumn{6}{|l|}{ Additive experiment } \\
\hline Algal treatment $(\mathrm{A})$ & 9.10 & 3 & 6.49 & 0.0007 & 11.8 \\
\hline Herbivore treatment $(\mathrm{H})$ & 14.09 & 3 & 10.04 & 0.0001 & 19.5 \\
\hline $\mathrm{A} \times \mathrm{H}$ & 11.62 & 9 & 2.76 & 0.0085 & 11.4 \\
\hline Error & 29.93 & 64 & & & 57.4 \\
\hline \multicolumn{6}{|l|}{ Substitutive experiment } \\
\hline Algal treatment $(\mathrm{A})$ & 451.32 & 3 & 99.37 & 0.0001 & 58.9 \\
\hline Herbivore treatment $(\mathrm{H})$ & 87.81 & 3 & 19.34 & 0.0001 & 11.0 \\
\hline $\mathrm{A} \times \mathrm{H}$ & 48.83 & 9 & 3.59 & 0.0003 & 4.6 \\
\hline Error & 166.53 & 110 & & & 25.5 \\
\hline
\end{tabular}

Notes: The "no herbivore" treatment was excluded here so that the relative importance of the algal and herbivore identity/richness effects could be directly compared (i.e., the design necessarily lacks a comparable "no algae" treatment). For the last column, $\omega^{2}$ is the magnitude of effects (the relative contribution expressed as the percentage of the total variance) for each factor (Graham and Edwards 2001).

change in algal wet mass that omitted the no-herbivore control so that we could evaluate the interactive treatment effects and the relative importance of algal and herbivore composition/richness by estimating their magnitude of effects, $\omega^{2}$ (Graham and Edwards 2001). This technique uses estimated variance components for each factor to determine its relative contribution to the total model variance. Differences among treatments in final algal wet mass were analyzed using one-factor ANOVA performed in the Fit Model platform of JMP to test for: (1) effects of algal group composition and richness in the absence of herbivores $(n=5$ in 2002 and 8 in 2003), (2) herbivore treatment effects across all pooled algal treatments ( $n=20$ in 2002 and 32 in 2003), and (3) herbivore treatment effects within each algal treatment ( $n=5$ in 2002 and 8 in 2003). Least square mean planned contrasts were performed to test for richness effects by comparing the polyculture treatment to all functional groups (as in Bruno et al. 2005, Duffy et al. 2005). Similarly, planned contrasts were used to compare herbivore-free controls to all herbivore treatments.

In an additive design, it is possible that an observed positive relationship between consumer richness and performance could be due solely to increased aggregate consumer density in the highest richness treatment rather than to the number of species (Schmitz 2007). We accounted for the higher animal densities in the grazer polycultures and measured the independent effects of grazer richness by comparing the summed performance of all three grazer monocultures with that of the grazer polycultures. This was done by summing the mean net effects of each of the three grazer monocultures on final algal biomass (i.e., [mean grazer-free control algal mass] - [mean algal mass] in the grazer treatments). We repeated this procedure for the mean net grazer effects for: (1) the algal monocultures, (2) the algal polycultures, and (3) all combined algal treatments, so that we could examine how changing algal group richness could influence the grazer richness effect once grazer density had been accounted for.

\section{RESUlts}

In the absence of herbivores, the algal group monocultures varied substantially in net growth in both experiments, with green algae, particularly Ulva, growing far more than reds or browns (Table 1, Fig. 2, left panels; $P=0.001$ for both tests). On average, algal group richness tended to enhance algal growth in the additive experiment, i.e., the final wet mass of the algal polyculture was marginally significantly greater than that of the average monoculture (Fig. 2A, left panel; $P=$ 0.067 , comparison of polyculture to all functional groups), but was not greater than the green alga group $(P=0.51)$, the most productive in monoculture. In this experiment, four of five algal species tended to grow better in polyculture than within their own functional group (Fig. 2A, right panel). One of those species, Polysiphonia harveyi, tripled its growth in the algal polyculture relative to the red functional group ( $t$ test, $P$ $=0.045)$. In the substitutive experiment there was no significant effect of algal group richness on net production (Fig. 2B, left panel; $P=0.818$ ) and of the six species only Gracilaria tikvahiae grew better in polyculture than in its functional group ( $t$ test, $P=$ 0.032 ). Several species grew poorly or lost mass during the substitutive experiment, which was performed during a warmer season and during a relatively warm year compared with the additive experiment.

Compared with herbivore-free controls, herbivore presence reduced algal biomass across all (pooled) algal treatments in both experiments, although this effect was stronger in the substitutive experiment (Fig. 3F; $P=$ 0.0002 ) than in the additive experiment (Fig. 3A; $P=$ $0.05)$. In the substitutive experiment, herbivore identity influenced final total algal biomass (Fig. 3F), and these effects were dependent on both consumer and algal identity. For example, urchins reduced algal biomass to a greater degree than did pinfish or amphipods (Fig. 3, 


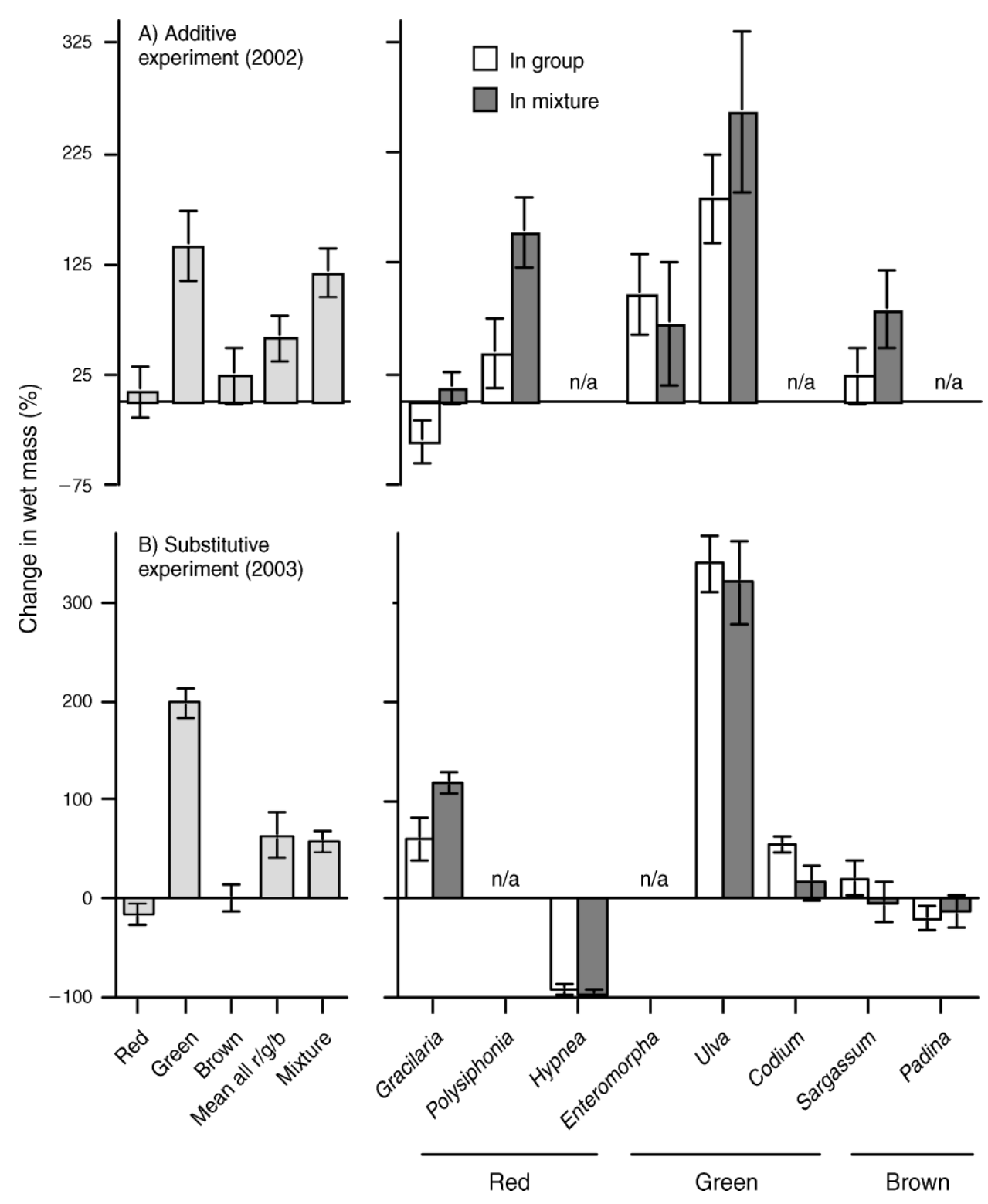

FIG. 2. Macroalgal performance in the absence of herbivores (change in mass, mean \pm SE) for (A) the additive experiment (2002) and (B) the substitutive experiment (2003). (Left panels) Responses of algal functional group monoculures and the three group polycultures $(n=5$ in 2002 and 8 in 2003). The average of all group monoculture replicates (i.e., the mean monoculture performance, $n=20$ in 2002 and 32 in 2003) is shown for comparison with the polyculture treatment (significantly higher growth of the polyculture would be indicative of a richness effect). (Right panels) Responses of individual macroalgal species grown with only species in its group (open bars) and with other functional groups in the three group polycultures (solid bars). Values are means \pm SE; n/a, not applicable.

right panels; $P=0.0001$ ), but this trend was not evident for brown algae (Fig. 3I; $P=0.18$ ). Similarly, in the additive experiment, pinfish tended to reduce green algal biomass more than amphipods and urchins did (Fig. 3C; $P=0.06$ ) but had no effect on brown or red algae (Fig. 3B, D).

In the additive experiment, the herbivore polycultures significantly reduced algal biomass to a greater degree than: (1) the average herbivore monoculture (Fig. 3A; $P$ $=0.0001)$, (2) pinfish alone $(P=0.02)$, which had the strongest effect of the herbivore monocultures in that experiment, and (3) the summed effect of all three monocultures (Table 2). The herbivore richness effect was dampened by increasing algal group richness (Table 2 ), however, this effect was only detected when herbivore density was accounted for (i.e., by summing the performance of the three monocultures) and was not evident in the initial analysis of the raw results (Fig. 4A). The herbivore richness effect also varied among the algal monocultures, as herbivore richness strongly affected 


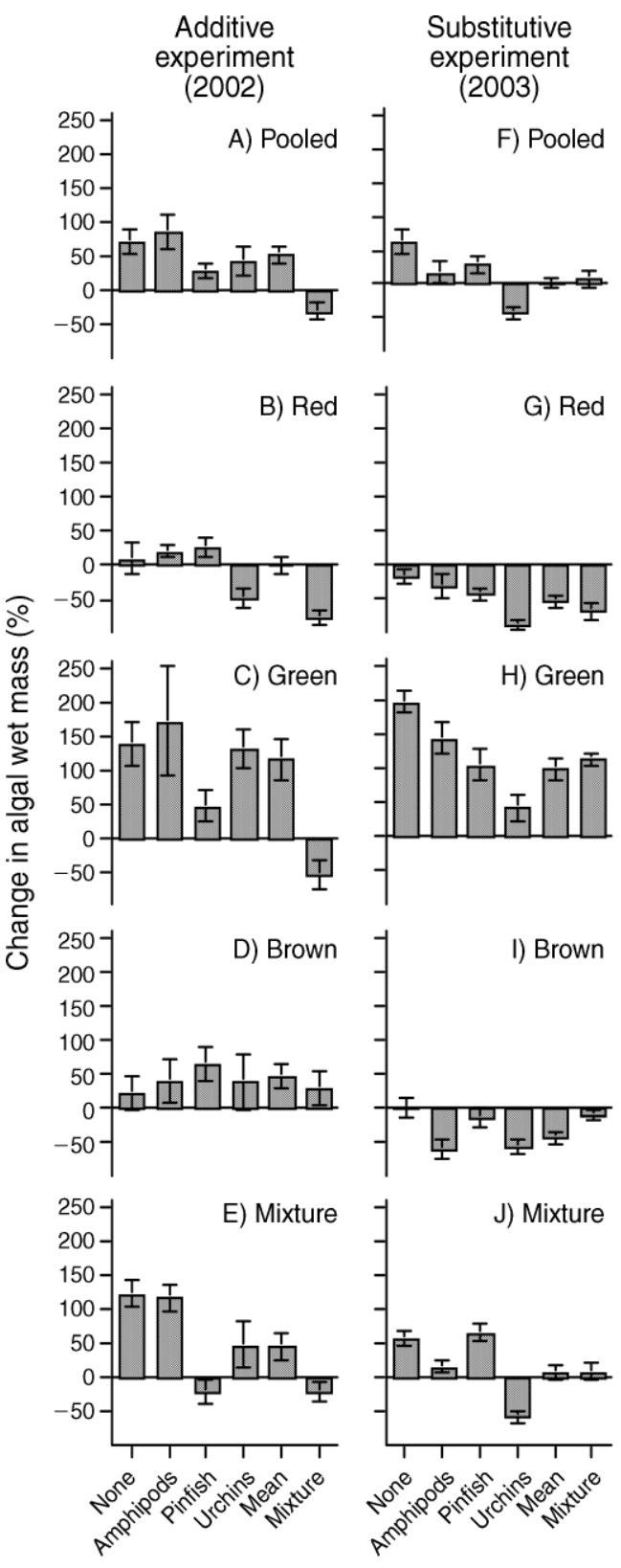

FIG. 3. Effects of herbivore species identity and richness and macroalgal group identity and richness on algal performance. (A, F) Pooled responses of the algal group monocultures ( $n=20$ in 2002 and 32 in 2003). (B-E, G-J) Responses of macroalgal group monocultures and polycultures. The average effects of all herbivore monoculture replicates $(n=60$ in 2002 and 96 in 2003 for the pooled responses, and $n=15$ in 2002 and 24 in 2003 for the unpooled responses in B-E and G-J) are shown for comparison with the herbivore polycultures. Values are means $\pm \mathrm{SE}$.

red $(P=0.0003)$ and green $(P=0.0025)$ algae but had no effect on browns (Fig. 3, left panels; $P=0.60$ ).

In contrast, in the substitutive experiment grazing in the herbivore polycultures did not differ from that in the average herbivore monoculture in any of the algae treatments (Fig. 3, right panels, Fig. 4). Additionally, the effects of the algal group composition and richness treatments explained a far greater percentage of the variance than the herbivore treatments in the substitutive experiment (Table 1). In fact, consumption of brown algae in the substitutive experiment tended to be reduced in the herbivore polycultures (Fig. 3I), likely as a result of very low amphipod abundances due to pinfish predation (Duffy and Hay 2000). At the beginning of the substitutive experiment, 210 amphipods were added to each amphipod monoculture and 70 were added to herbivore polycultures. Amphipod populations increased substantially in the amphipod monocultures mainly due to local reproduction, but decreased dramatically in the herbivore polyculture (Fig. 5). The few amphipods present in the other treatments were due to contamination via the water supply.

\section{DisCUSSION}

The influence of algal and herbivore richness on algal biomass accumulation differed substantially between the two experiments. In the additive experiment, algal group richness had a fairly strong effect on net biomass production in the absence of herbivores (Fig. 2A). A large number of studies, primarily using herbaceous terrestrial plants, have found similar enhancement of production by plant species or functional group richness (Hooper et al. 2005). However, most previous experiments based on marine algae have found either relatively subtle or no richness effects (Bruno et al. 2005, 2006, Stachowicz et al. 2007). A recent review of marine biodiversity-ecosystem functioning studies found that the species composition of primary producers usually had much stronger effects on biomass accumulation, explaining up to $76 \%$ of variance (mean $\omega^{2}=0.48, n=8$ experiments), compared to richness effects, which explained only 1-9\% of variance (Stachowicz et al. 2007). One major difference with previous marine studies was that our experiments were based on algal functional groups rather than algal species and thus incorporated a greater range of species trait differences, potentially facilitating a variety of mechanisms that are known to underlie plant richness effects.

TABLE 2. Mean net effects of herbivore three-species polycultures and the summed mean effects of the three herbivore monocultures on final algal biomass in the additive experiment.

\begin{tabular}{lcc}
\hline \hline Algal treatment & $\begin{array}{c}\text { Combined } \\
\text { net herbivore } \\
\text { monoculture effect }\end{array}$ & $\begin{array}{c}\text { Net } \\
\text { polyculture } \\
\text { effect }\end{array}$ \\
\hline One algal group & -6.81 & -91.8 \\
Three algal groups & -216.18 & -138.18 \\
All algal treatments & -59.15 & -103.40 \\
\hline
\end{tabular}

Notes: Values are percentage change in wet mass relative to algal growth in the control (no herbivore) treatments (i.e., [mean control algal mass] - [mean algal mass] in the grazer treatment). All calculations are based on mean values for each treatment combination. 


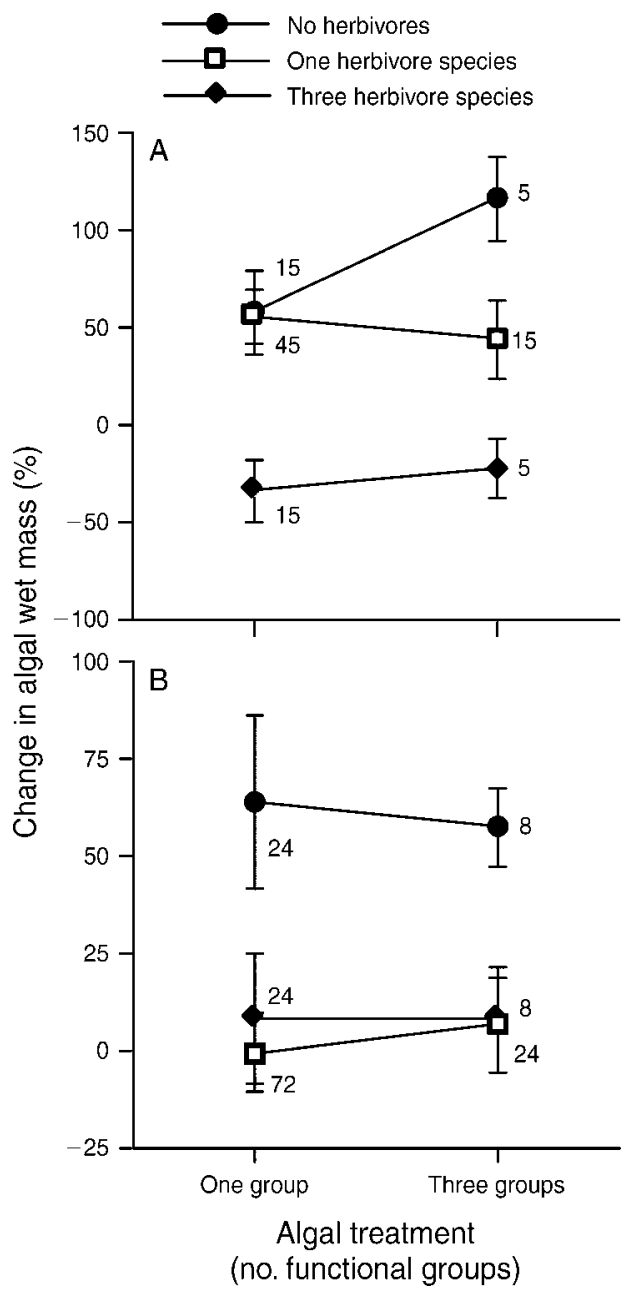

FIG. 4. Independent and interactive effects of herbivore presence and species richness and algal group richness on algal performance (means $\pm \mathrm{SE}$ ) in (A) the additive experiment and (B) the susbtitutive experiment. Numbers next to symbols are sample sizes.

Only one-half (8 of 16) of recent marine field and mesocosm experiments found evidence for an effect of algal or plant richness on primary producer biomass or production (Stachowicz et al. 2007). Likewise, in the present study, algal group richness increased net production in only one of our two experiments. Several factors including resource availability and environmental heterogeneity can potentially influence the strength of plant richness effects (Fridley 2001, 2002). The inclusion of consumers might also modify the effects of plant richness on biomass, for example, by strengthening positive effects via associational defenses (Hay 1986). However, two previous experiments in microbial systems (Fox 2004, Gamfeldt et al. 2005) and one in grassland (Mulder et al. 1999) found that, when consumers were present, the effects of plant richness on primary productivity were relatively weak, transient, or absent. Likewise, in our first experiment, algal group richness more strongly enhanced final algal biomass when herbivores were absent than when they were present (Fig. 4). But it is possible that greater consumption masked higher primary productivity in the high algal richness treatment with grazers. This finding highlights the fact that herbivores can decouple the relationship between plant productivity and biomass (see also Mulder et al. 1999) and the importance of including consumer-free controls, even in multi-trophic biodiversity experiments.

The results of the additive experiment also indicate that three-species grazer polycultures reduced algal biomass to a far greater extent than either the average herbivore monoculture, or the one herbivore species with the largest effect (Fig. 3A). The effect of herbivore richness in this experiment was very similar in magnitude, though opposite in sign, to that of algal richness (Fig. 4A, Table 1). This evidence adds to a growing list of studies that have demonstrated the substantial effects of herbivore and carnivore richness on prey consumption and abundance (Cardinale et al. 2003, Duffy et al. 2003, Finke and Denno 2004, Bruno and O'Connor 2005, Byrnes et al. 2006), although the direction of consumer richness effects can be quite context dependent (Bruno and O'Connor 2005, Bruno and Cardinale 2008).

The observed herbivore richness effect in the additive experiment could have been caused by several factors including dietary complementarity, facilitation, a positive selection effect, or the greater total herbivore density in polyculture. Consistent with a contribution of complementarity, the grazers we studied showed some degree of dietary differentiation. Pinfish (Lagodon rhomboides) prefer to consume the green alga Enteromorpha (Fig. 3C), avoid the introduced green Codium (Fig. $3 \mathrm{H})$, eat some red algae including Polysiphonia, and generally find brown algae unpalatable (Fig. 3D, I)

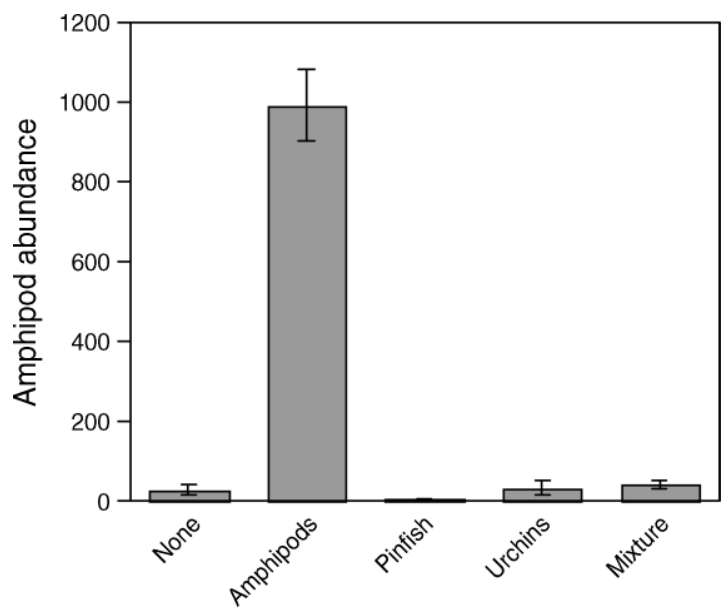

FIG. 5. Abundance of the amphipod Ampithoe longimana in the five herbivore treatments at the end of the substitutive experiment (means $\pm \mathrm{SE}$; data are pooled across algal treatments, $n=32$ ). 


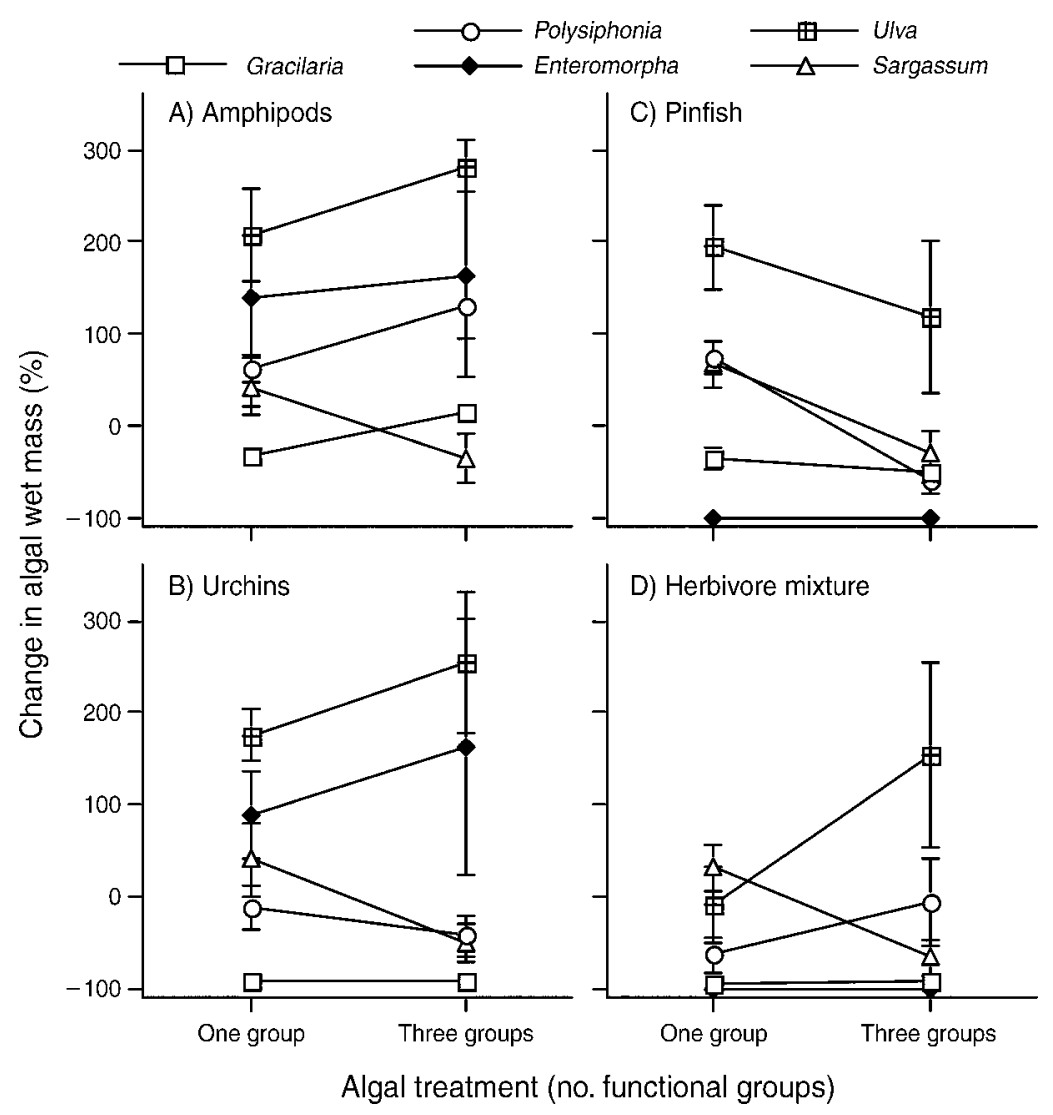

FIG. 6. Effects of each herbivore species and the grazer polycultures and algal group richness on the performance of each algal species in the additive experiment. Values are means $\pm \mathrm{SE} ; n=5$. Some error bars are too small to be visible.

(Duffy and Hay 2000). And the urchin Arbacia punctulata has a similar, though somewhat broader diet (Bolser and Hay 1996). In contrast, amphipods, particularly Ampithoe longimana, have strong grazing effects on most brown algae, will consume Enteromorpha, and generally avoid red algae (Duffy and Hay 2000, Bruno and O'Connor 2005). It is possible that these herbivore-specific effects on different algal functional groups (Fig. 3) contributed to the enhanced net grazing in herbivore polycultures in the additive experiment (Duffy and Stachowicz 2006). There is also evidence that facilitation (or a related mechanism) may have enhanced grazer performance in species polycultures. For example, urchins and pinfish were the only species to significantly reduce red and green algal mass, respectively, but grazing on both algal groups was greater in the high-herbivore richness treatment (Fig. 3B, C).

Because we used an additive design for the herbivore treatments in the additive experiment, grazer richness and density were confounded. However, the performance of the grazer polycultures was greater than the summed effect of all three monocultures (Table 2), i.e., the effect of increasing herbivore richness was not simply additive but was instead multiplicative or "emergent" (Sih et al. 1998, Schmitz and Sokol-Hessner 2002). Thus the increase in total herbivore abundance in the polycultures in the additive experiment was clearly not the sole cause of the observed herbivore richness effect. Furthermore, pinfish also probably reduced amphipod densities in the grazer polycultures in the additive experiment as they did in the substitutive experiment (Fig. 5). This intraguild predation would have resulted in total grazer density in the polycultures less than the sum of monoculture densities. Thus, our additivity test for grazer richness effects is conservative.

In the substitutive experiment, we found strong effects of herbivores, including the consumption of brown algae by amphipod and urchin monocultures (which did not occur in the additive experiment), but no evidence of herbivore richness effects (Fig. 3, right panels). This could have been caused in part by substantial differences in abiotic conditions (the additive experiment was run in the fall, while the substitutive experiment was performed during the summer), algal species composition, or grazer monoculture densities. Another likely explanation is the striking degree of intraguild predation we observed (Fig. 5), which could have negated most known mechanisms underlying consumer biodiversity effects (Finke and Denno 2004, 2005, Bruno and Cardinale 2008). Early in their life cycle (i.e., during the summer when the substitutive experiment was performed) pinfish are 
omnivores and are one of the main predators of amphipods (Stoner 1980, Duffy and Hay 2000). Predation by pinfish almost certainly explains why amphipod populations were so small in the polyculture treatments in the substitutive experiment (Fig. 5). Without amphipods, there was reduced consumption of brown algae in the herbivore polycultures compared to the amphipod monocultures (Fig. 3I). Finally, abundant amphipod prey could have influenced the foraging behavior and choices of pinfish, thereby influencing their function as herbivores. Such negative intraguild interactions are a feature of most natural food webs and could become more frequent and important as species richness and food web complexity increases (Polis and Strong 1996, Holt and Polis 1997, Finke and Denno 2004).

One of the benefits of manipulating both predator and prey composition and richness in a factorial design is the ability to test for interactions among diversity at different levels that are theoretically predicted (Duffy 2002, Duffy et al. 2007) but very difficult to measure. In the additive experiment the effects of increasing herbivore richness, as predicted (Duffy 2003, Hillebrand and Cardinale 2004), tended to be dampened by increasing algal group richness, although this effect was only evident once we controlled for grazer density (Table 2). It is not clear what mechanism(s) led to this result, but one possibility is that negative interactions among the herbivores reduced their ability to consume a diverse plant assemblage. For example, intraguild predation by pinfish of amphipods would have greatly reduced the consumption of brown algae in the algal group polycultures. Alternatively, increased primary production (due to increased algal richness) could have reduced the ability of grazers to suppress algal biomass, effectively compensating for the increased grazer richness. The herbivore richness effect was also dependent on algal composition and was not significant for the brown algal monoculture (Fig. 3D). Rates of herbivory were highly dependent on herbivore and algal identity, reflecting the dietary specificity of these benthic marine grazers, possibly caused by consumer-specific algal chemical and structural defenses (Hay et al. 1987, 1988). Increasing algal group richness did not reduce grazing overall (Fig. 4). However, this result masked a variety of nearly balanced positive and negative effects of algal richness on the consumption of particular species (Fig. 6), and the phenomenon was highly dependent on herbivore identity.

Exploring the effects of biodiversity on ecosystem functioning in a multi-trophic context is an important frontier for future research (Worm and Duffy 2003, Petchey et al. 2004, Duffy et al. 2007). Nearly all early biodiversity experiments focused on plant richness and explicitly or effectively excluded grazers. This was an important step and revealed a variety of surprising mechanisms based on complex plant-plant interactions that can underlie plant richness effects (Hooper et al.
2005). But all plants, and all prey, coexist with consumers, so it is important for ecologists to begin to consider consumer composition and richness to understand the relative importance and context dependency of biodiversity effects in realistic trophic settings.

Furthermore, the diversity of plants and animals is changing, often quite rapidly, due to a variety of human activities and frequently in opposite directions. For example, most exotic species are plants or low level consumers (Byrnes et al. 2007). In many terrestrial and aquatic habitats, species invasions have quite substantially increased the richness of lower trophic levels (Sax and Gaines 2003). In contrast, predators, particularly large-bodied vertebrates, are more susceptible to anthropogenic extinction than most plants and small animals (Duffy 2002, 2003, Byrnes et al. 2007). As a result the diversity of top carnivores is generally decreasing (Terborgh et al. 2001, Myers and Worm 2003, Worm et al. 2005). The combination of these and other processes are skewing food webs and trophic functioning by altering the relative richness of adjacent trophic levels (Bruno and Cardinale 2008). We are only beginning to understand, from theory (Thebault and Loreau 2003, Dobson et al. 2006, Thebault et al. 2007) and experiments (Downing 2005, Duffy et al. 2005, Wojdak 2005), how such modification to food web topology will influence ecosystem dynamics.

\section{AcKNOWLEDGMENTS}

We thank M. Dolan, J. Douglass, K. France, B. Huntington, J. Kertesz, M. Kintzing, S. Taylor, and the staff of UNC-CH's Institute of Marine Science (IMS) for all of their assistance and J. Wells, the former director of IMS, for all of his support. This research was funded in part by the National Science Foundation (OCE 0327191), an NSF Predoctoral Fellowship to S. C. Lee, and the University of North Carolina, Chapel Hill.

\section{Literature Cited}

Aquilino, K. M., B. J. Cardinale, and A. R. Ives. 2005. Reciprocal effects of host plant and natural enemy diversity on herbivore suppression: an empirical study of a model tritrophic system. Oikos 108:275-282.

Balvanera, P., A. B. Pfisterer, N. Buchmann, J. S. He, T. Nakashizuka, D. Raffaelli, and B. Schmid. 2006. Quantifying the evidence for biodiversity effects on ecosystem functioning and services. Ecology Letters 9:1146-1156.

Bolser, R. C., and M. E. Hay. 1996. Are tropical plants better defended? Palatability and defenses of temperate vs. tropical seaweeds. Ecology 77:2269-2286.

Bruno, J. F., K. E. Boyer, J. E. Duffy, S. C. Lee, and J. S. Kertesz. 2005. Effects of macroalgal species identity and richness on primary production in benthic marine communities. Ecology Letters 8:1165-1174.

Bruno, J. F., and B. J. Cardinale. 2008. Cascading effects of predator diversity. Frontiers in Ecology and the Environment 6. [doi: 10.1890/070136]

Bruno, J. F., S. C. Lee, J. S. Kertesz, R. C. Carpenter, Z. T. Long, and J. E. Duffy. 2006. Partitioning the effects of algal species identity and richness on benthic marine primary production. Oikos 115:170-178.

Bruno, J. F., and M. I. O'Connor. 2005. Cascading effects of predator diversity and omnivory in a marine food web. Ecology Letters 8:1048-1056. 
Byrnes, J. E., P. L. Reynolds, and J. J. Stachowicz. 2007. Invasions and extinctions reshape coastal marine food webs. PLoS One 2:e295.

Byrnes, J., J. J. Stachowicz, K. M. Hultgren, A. Randall Hughes, S. V. Olyarnik, and C. S. Thornber. 2006. Predator diversity strengthens trophic cascades in kelp forests by modifying herbivore behaviour. Ecology Letters 9:61-71.

Callaway, J. C., G. Sullivan, and J. B. Zedler. 2003. Species-rich plantings increase biomass and nitrigen accumulation in a wetland restoration experiment. Ecological Applications 13: $1626-1639$.

Cardinale, B. J., C. T. Harvey, K. Gross, and A. R. Ives. 2003. Biodiversity and biocontrol: emergent impacts of a multienemy assemblage on pest suppression and crop yield in an agroecosystem. Ecology Letters 6:857-865.

Cardinale, B. J., M. A. Palmer, and S. L. Collins. 2002. Species diversity enhances ecosystem functioning through interspecific facilitation. Nature 415:426-429.

Cardinale, B. J., D. S. Srivastava, J. E. Duffy, J. P. Wright, A. L. Downing, M. Sankaran, and C. Jouseau. 2006. Effects of biodiversity on the functioning of trophic groups and ecosystems. Nature 443:989-992.

Carpenter, R. C. 1986. Partitioning herbivory and its effects on coral-reef algal communities. Ecological Monographs 56: 345-363.

Cronin, G., and M. E. Hay. 1996a. Susceptibility to herbivores depends on recent history of both the plant and animal. Ecology 77:1531-1543.

Cronin, G., and M. E. Hay. 1996b. Within plant variation in seaweed palatability and chemical defenses: optimal defense theory versus the growth differentiation balance hypothesis. Oecologia 105:361-368.

Dobson, A., D. Lodge, J. Alder, G. S. Cumming, J. Keymer, J. McGlade, H. Mooney, J. A. Rusak, O. Sala, V. Wolters, D. Wall, R. Winfree, and M. A. Xenopoulos. 2006. Habitat loss, trophic collapse, and the decline of ecosystem services. Ecology 87:1915-1924.

Downing, A. L. 2005. Relative effects of species composition and richness on ecosystem properties in ponds. Ecology 86: 701-715.

Duffy, J. E. 2002. Biodiversity and ecosystem function: the consumer connection. Oikos 99:201-219.

Duffy, J. E. 2003. Biodiversity loss, trophic skew and ecosystem functioning. Ecology Letters 6:680-687.

Duffy, J. E., B. J. Cardinale, K. E. France, P. B. McIntyre, E. Thebault, and M. Loreau. 2007. The functional role of biodiversity in ecosystems: incorporating trophic complexity. Ecology Letters 10:522-538.

Duffy, J. E., and M. E. Hay. 1991. Food and shelter as determinants of food choice by an herbivorous marine amphipod. Ecology 72:1286-1298.

Duffy, J. E., and M. E. Hay. 1994. Herbivore resistance to seaweed chemical defense: the roles of mobility and predation risk. Ecology 75:1304-1319.

Duffy, J. E., and M. E. Hay. 2000. Strong impacts of grazing amphipods on the organization of a benthic community. Ecological Monographs 70:237-263.

Duffy, J. E., J. P. Richardson, and E. A. Canuel. 2003. Grazer diversity effects on ecosystem functioning in seagrass beds. Ecology Letters 6:637-645.

Duffy, J. E., J. P. Richardson, and K. E. France. 2005. Ecosystem consequences of diversity depend on food chain length in estuarine vegetation. Ecology Letters 8:301-309.

Duffy, J. E., and J. J. Stachowicz. 2006. Why biodiversity is important to oceanography: potential roles of genetic, species, and trophic diversity in pelagic ecosystem processes. Marine Ecology Progress Series 311:179-189.

Finke, D. L., and R. F. Denno. 2004. Predator diversity dampens trophic cascades. Nature 429:407-410.
Finke, D. L., and R. F. Denno. 2005. Predator diversity and the functioning of ecosystems: the role of intraguild predation in dampening trophic cascades. Ecology Letters 8:1299-1306.

Fox, J. W. 2004. Effects of algal and herbivore diversity on the partitioning of biomass within and among trophic levels. Ecology 85:549-559.

Fridley, J. D. 2001. The influence of species diversity on ecosystem productivity: how, where, and why? Oikos 93:514 526.

Fridley, J. D. 2002. Resource availability dominates and alters the relationship between species diversity and ecosystem productivity in experimental plant communities. Oecologia 132:271-277.

Gamfeldt, L., H. Hillebrand, and P. R. Jonsson. 2005. Species richness changes across two trophic levels simultaneously affect prey and consumer biomass. Ecology Letters 8:696703.

Graham, M. H., and M. S. Edwards. 2001. Statistical significance versus fit: estimating the importance of individual factors in ecological analysis of variance. Oikos 93:505-513.

Hay, M. E. 1986. Associational plant defenses and the maintenance of species diversity: turning competitors into accomplices. American Naturalist 128:617-641.

Hay, M. E., J. E. Duffy, and C. A. Pfister. 1987. Chemical defense against different marine herbivores: are amphipods insect equivalents. Ecology 68:1567-1580.

Hay, M. E., P. E. Renaud, and W. Fenical. 1988. Large mobile versus small sedentary herbivores and their resistance to seaweed chemical defenses. Oecologia 75:246-252.

Hay, M. E., and J. P. Sutherland. 1988. The ecology of rubble structures of the south Atlantic bight: a community profile. United States Fish and Wildlife Service, Department of the Interior, Washington, D.C., USA.

Hillebrand, H., and B. J. Cardinale. 2004. Consumer effects decline with prey diversity. Ecology Letters 7:192-201.

Holmlund, M. B., C. H. Peterson, and M. E. Hay. 1990. Does algal morphology affect amphipod susceptibility to fish predation. Journal of Experimental Marine Biology and Ecology 139:65-83.

Holt, R. D., and M. Loreau. 2002. Biodiversity and ecosystem functioning: the role of trophic interactions and the importance of system openness. Pages 246-262 in A. P. Kinzig, S. W. Pacala, and D. Tilman, editors. The functional consequences of biodiversity: empirical progress and theoretical extensions. Princeton University Press, Princeton, New Jersey, USA.

Holt, R. D., and G. A. Polis. 1997. A theoretical framework for intraguild predation. American Naturalist 149:745-764.

Hooper, D. U., et al. 2005. Effects of biodiversity on ecosystem functioning: a consensus of current knowledge. Ecological Monographs 75:3-35.

Hughes, A. R., and J. J. Stachowicz. 2004. Genetic diversity enhances the resistance of a seagrass ecosystem to disturbance. Proceedings of the National Academy of Sciences 101: 8998-9002.

Jonsson, M., and B. Malmqvist. 2000. Ecosystem process rate increases with animal species richness: evidence from leafeating, aquatic insects. Oikos 89:519-523.

Leibold, M. A. 1996. A graphical model of keystone predators in food webs: trophic regulation of abundance, incidence, and diversity patterns in communities. American Naturalist 147:784-812.

Leibold, M. A., J. M. Chase, J. B. Shurin, and A. L. Downing. 1997. Species turnover and the regulation of trophic structure. Annual Review of Ecology and Systematics 28: 467-494.

Long, Z. T., J. F. Bruno, and J. E. Duffy. 2007. Biodiversity mediates productivity through different mechanisms at adjacent trophic levels. Ecology 88:2821-2829. 
Lubchenco, J. 1978. Plant species diversity in a marine intertidal community: importance of herbivore food preference and algal competitive abilities. American Naturalist 112: 23-39.

Mikola, J., and H. Setälä. 1998. Relating species diversity to ecosystem functioning: mechanistic backgrounds and experimental approach with a decomposer food web. Oikos 83: 180-194.

Miller, M. W., and M. E. Hay. 1996. Coral-seaweed-grazernutrient interactions on temperate reefs. Ecological Monographs 66:323-344.

Mulder, C. P. H., J. Koricheva, K. Huss-Danell, P. Hogberg, and J. Joshi. 1999. Insects affect relationships between plant species richness and ecosystem processes. Ecology Letters 2: 237-246.

Myers, R. A., and B. Worm. 2003. Rapid worldwide depletion of predatory fish communities. Nature 423:280-283.

Naeem, S., and S. B. Li. 1998. Consumer species richness and autotrophic biomass. Ecology 79:2603-2615.

Norberg, J. 2000. Resource-niche complementarity and autotrophic compensation determines ecosystem-level responses to increased cladoceran species richness. Oecologia 122:264 272.

O'Connor, N. E., and J. F. Bruno. 2007. Predatory fish loss affects the structure and functioning of a model marine food web. Oikos 116:2027-2038.

O'Connor, N. E., and T. P. Crowe. 2005. Biodiversity loss and ecosystem functioning: distinguishing between number and identity of species. Ecology 86:1783-1796.

Petchey, O. L., A. L. Downing, G. G. Mittelbach, L. Persson, C. F. Steiner, P. H. Warren, and G. Woodward. 2004. Species loss and the structure and functioning of multitrophic aquatic systems. Oikos 104:467-478.

Polis, G. A., and D. R. Strong. 1996. Food web complexity and community dynamics. American Naturalist 147:813-846.

Reusch, T. B. H., A. Ehlers, A. Hammerli, and B. Worm. 2005. Ecosystem recovery after climatic extremes enhanced by genotypic diversity. Proceedings of the National Academy of Sciences (USA) 102:2826-2831.

Ruesink, J. L., and D. S. Srivastava. 2001. Numerical and per capita responses to species loss: mechanisms maintaining ecosystem function in a community of stream insect detritivores. Oikos 93:221-234.
Sax, D. F., and S. D. Gaines. 2003. Species diversity: from global decreases to local increases. Trends in Ecology and Evolution 18:561-566.

Schmitz, O. J. 2007. Predator diversity and trophic interactions. Ecology 88:2415-2426.

Schmitz, O. J., and L. Sokol-Hessner. 2002. Linearity in the aggregate effects of multiple predators in a food web. Ecology Letters 5:168-172.

Sih, A., G. Englund, and D. Wooster. 1998. Emergent impacts of multiple predators on prey. Trends in Ecology and Evolution 13:350-355.

Stachowicz, J. J., J. F. Bruno, and J. E. Duffy. 2007. Understanding the effects of marine biodiversity on communities and ecosystems. Annual Review of Ecology, Evolution, and Systematics 38:739-766.

Stoner, A. W. 1980. Feeding ecology of Lagodon rhomboides (Pisces: Sparidae): variation and functional responses. Fishery Bulletin 78:337-352.

Terborgh, J., L. Lopez, P. Nuñez, M. Rao, G. Shahabuddin, G. Orihuela, M. Riveros, R. Ascanio, G. H. Adler, T. D. Lambert, and L. Balbas. 2001. Ecological meltdown in predator-free forest fragments. Science 294:1923-1926.

Thebault, E., V. Huber, and M. Loreau. 2007. Cascading extinctions and ecosystem functioning: contrasting effects of diversity depending on food web structure. Oikos 116:163173.

Thebault, E., and M. Loreau. 2003. Food-web constraints on biodiversity-ecosystem functioning relationships. Proceedings of the National Academy of Sciences (USA) 100:1494914954.

Tilman, D., P. B. Reich, J. Knops, D. Wedin, T. Mielke, and C. Lehman. 2001. Diversity and productivity in a long-term grassland experiment. Science 294:843-845.

Wojdak, J. M. 2005. Relative strength of top-down, bottom-up, and consumer species richness effects on pond ecosystems. Ecological Monographs 75:489-504.

Worm, B., and J. E. Duffy. 2003. Biodiversity, productivity and stability in real food webs. Trends in Ecology and Evolution 18:628-632.

Worm, B., M. Sandow, A. Oschlies, H. K. Lotze, and R. A. Myers. 2005. Global patterns of predator diversity in the open oceans. Science 309:1365-1369. 